\section{A Comparison of the CARATKids and CARAT10 Questionnaires for the Evaluation of Control of Asthma and Allergic Rhinitis in Adolescents}

Pereira Martins $\mathrm{S}^{1}$, Teixeira $\mathrm{PM}^{1,2}$, Yaphe $\mathrm{J}^{1,2}$, Fonseca $\mathrm{J}^{3,4}$, Correia de Sousa $\mathbf{J}^{1,2,5}$

${ }^{1}$ School of Medicine, University of Minho, Braga, Portugal ${ }^{2} I C V S / 3 B$ 's - PT Government Associate Laboratory, Life and Health Sciences Research Institute (ICVS), School of Medicine, University of Minho, Campus de Gualtar, Braga, Portugal ${ }^{3}$ CINTESIS - Centre for Research in Health Technologies and Information Systems and Information and Decision Sciences Department, Faculty of Medicine, University of Porto, Porto, Portugal ${ }^{4}$ Allergy Unit, CUF Porto Institute \& Hospital, Porto, Portugal ${ }^{5}$ Horizonte Family Health Unit, Matosinhos, Porto, Portugal

J Investig Allergol Clin Immunol 2019; Vol. 29(3): 239-240 doi: 10.18176/jiaci.0365

Key words: CARAT. Asthma. Allergic rhinitis.

Palabras clave: CARAT. Asma. Rinitis alérgica.

The Control of Allergic Rhinitis and Asthma Test (CARAT) was introduced to assess control of allergic rhinitis and asthma (ARA) simultaneously. It is the first tool to implement ARIA guidelines in clinical practice [1-5].

CARAT10 was developed for adults [5], and CARATKids was designed for children aged 6 to 12 years [6]. There is no validated questionnaire to assess control of ARA in patients between the ages of 12 to 17 years.

This study compares the psychometric properties of the 2 currently available questionnaires for assessment of control of ARA in a population of adolescents aged 12-17 years.

Approval was obtained from the Ethics Committee of Braga Hospital and from the Ethics Committee of the School of Medicine of the University of Minho, Braga, Portugal.

A nonrandom consecutive sample of participants aged 12-17 years with a diagnosis of ARA was recruited from patients attending the Pediatric Allergology Clinic at Braga Hospital. Patients with other coexisting chronic or respiratory diseases that could influence the results were excluded.

The adolescents were asked to complete the Asthma Control Test (ACT) [7] and the CARAT10 [5] and CARATKids [6] questionnaires. Participants were assessed by their doctor, and the researcher conducted a short interview with the participants to assess the acceptability of the questionnaires.

Medical assessment covered 6 parameters: (1) the classification of rhinitis as intermittent or persistent and mild

or moderate/severe, as described in the ARIA guidelines; (2) a 10-cm visual analog scale (VAS, from 1 to 10) for rating disease control in the previous 4 weeks; (3) a classification of asthma control, according to the GINA criteria, as controlled, partly controlled, and uncontrolled; (4) a VAS for rating disease control in the previous 4 weeks; (5) atopy; and (6) treatment.

Categorical variables were expressed as absolute and relative frequencies. The Pearson or Spearman and intraclass correlation coefficient (ICC) were used to study the correlation and agreement between the CARAT and ACT scales and the CARAT and the medical evaluation, which included the VAS scores and the ARIA and GINA classifications.

The study included 103 patients (64\% males). The most frequent comorbidities were a personal and/or family history of atopy.

Associations between the questionnaires and the medical evaluation were lower than expected (Pearson correlation $\mathrm{r}<0.40$, and ICC $<0.5$ ). The correlation between the CARAT10 scores and VAS scores for the 14-15 and 16-17 year groups met the a priori prediction $(\mathrm{r}>0.40)$. No significant differences were found for the associations between questionnaires and the medical evaluation before and after the consultation. Similarly, no association was found with the parents' level of education.

Most participants (62\%) said they preferred CARATKids to CARAT10. They found it easier to complete (36 participants),

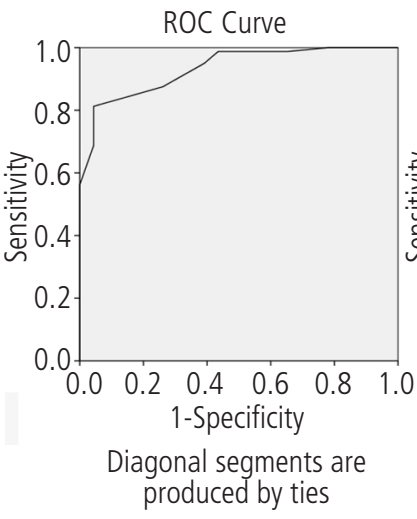

\begin{tabular}{lcc} 
& CARAT10a & CARATKids \\
\hline $\begin{array}{l}\text { Area under } \\
\text { the curve }\end{array}$ & 0.933 & 0.873 \\
Cut-off & 14 & 6 \\
Sensitivity & 0.8775 & 0.913 \\
Specificity & 0.739 & 0.650 \\
\hline
\end{tabular}

Figure. Receiver operating characteristic curves of the ACT with CARAT and with CARATKids. 
faster to complete (14 participants), more appealing (7 participants), more complete, and more user-friendly than the CARAT10.

The results suggest that both CARAT10 and CARATKids can be used to assess the control of asthma in patients aged 12 to 17 years. The CARAT10 questionnaire can be used in patients from age 14 years to evaluate control of ARA.

The correlation coefficients met the a priori predictions for these instruments, suggesting that they can be used to evaluate the control of asthma in this population. The CARAT10a subscore had a higher correlation with the ACT, as expected, because, like the ACT, it only assesses the control of asthma, while CARATKids assesses the control of ARA. Our results favor the use of CARAT10 among patients aged 14 to 17 years [8].

ROC curves were constructed for the CARATKids and CARAT10 scores against the ACT (Figure). For adolescents, new cut-off values for these questionnaires may need to be considered. For CARATKids, we suggest a cut-off score of $>6$ points for uncontrolled asthma, with a sensitivity of $91 \%$ and a specificity of $65 \%$. This is in agreement with previous proposals for this questionnaire [6].

For CARAT10, ROC curves were also analyzed in relation to the medical VAS assessment. A cut-off value of 21 indicated the best balance between sensitivity and specificity.

CARAT10 can be used for the evaluation of ARA in patients aged 14 years and onward. CARATKids and CARAT10 may both be used for the evaluation of asthma in patients aged 12 to 17 years. Further studies are needed to assess whether new cut-off values should be established for patients aged 14 to 17 years.

\section{Acknowledgments}

We are grateful to the Departments of Pediatrics and Allergology at Braga Hospital, especially Drs Augusta Gonçalves, Carmen Botelho, Carla Moreira, Ariana Afonso, and Mariana Couto.

\section{Funding}

Financial support for this work was provided by FEDER funds through the Operational Programme Competitiveness Factors - COMPETE and National Funds through FCTFoundation for Science and Technology under project POCI-01-0145-FEDER--007038 and project NORTE01-0145-FEDER-000013, supported by Norte Portugal Regional Operational Programme (NORTE 2020), under the PORTUGAL 2020 Partnership Agreement, through the European Regional Development Fund (ERDF).

\section{Conflicts of Interest}

The authors declare that they have no conflicts of interests.

\section{References}

1. Bousquet J, Vignola AM, Demoly P. Links between rhinitis and asthma. Allergy. 2003;58:691-06.
2. Global Initiative for Asthma. Global strategy for Asthma Management and Prevention 2014. Available from: www. ginasthma.org

3. Bateman ED, Hurd SS, Barnes PJ, Bousquet J, Drazen JM, FitzGerald $\mathrm{M}$, et al. Global strategy for asthma management and prevention: GINA executive summary. Eur Respir J. 2008;31(1):143-78.

4. Bousquet J, Reid J, Van Weel C, Baena Cagnani C, Canonica GW, Demoly $P$, et al. Allergic rhinitis management pocket reference 2008. Allergy. 2008;63(8):990-6.

5. Fonseca J, Nogueira-Silva L, Morais-Almeida M, Sa-Sousa A, Azevedo L, Ferreira J, et al. Control of Allergic Rhinitis and Asthma Test (CARAT) can be used to assess individual patients over time. Clin Trans Allergy. 2012;2:16.

6. Linhares D, Fonseca J, Borrego L, Matos A, Pereira A, Sousa A, et al. Validation of Control of Allergic Rhinitis and Asthma Test for Children (CARATKids) - a prospective multicenter study. Pediatr Allergy Immunol. 2014;25:173-9.

7. Schatz M, Mosen DM, Kosinski M, Vollmer WM, Magid DJ, O'Connor E, et al. Validity of the Asthma Control Test completed at home. Am J Manag Care. 2007;13(12):661-7.

8. O'Byrne P, Reddel H, Eriksson G, Ostlund O, Peterson S, Sears $M$, et al. Measuring asthma control: a comparison of three classification systems. Eur Respir J. 2010;36(2):269-76.

- Manuscript received November 21, 2017; accepted for publication December 13, 2018.

Pedro M Teixeira

Life and Health Sciences Research Institute (ICVS) Universidade do Minho Campus de Gualtar 4710-057 Braga Portugal

E-mail: teixeira.pms@gmail.com 